\title{
Employment Adjustment at the Firm Level. A Theoretical Model and an Empirical Investigation for West German Manufacturing Firms
}

\section{Werner Smolny}

Abstract. In this paper, employment adjustment at the firm level is estimated with a large panel of business survey data from West German manufacturing. The specification is based on a framework of monopolistic competition in the product market. Special emphasis is devoted to the analysis of the impact of demand uncertainty, capacity constraints, technological change and competition. The empirical results reveal that demand uncertainty and capacity constraints significantly affect employment adjustment. Innovative firms are more successful; they increase employment and exhibit a higher utilization of capacities. Employment adjustment also depends on competition. In monopolistic markets, the volatility of employment is higher.

\section{Introduction}

Long-lasting periods of high unemployment in Europe enhanced the interest in the determinants of firms' labour demand. One theme of the discussion on the causes of unemployment are effects of technological change on labour demand and employment. ${ }^{1}$ In

Prof. Dr. Werner Smolny, Faculty of Economics, Ruhr-University Bochum, GC3-58, D-44780 Bochum, Germany. Tel. +49 23432 28341; Fax +49 23432 14273 e-mail: Werner.Smolny@Ruhr-Uni-Bochum.de.

This paper is part of the research project 'Growth and Innovations'. I like to thank W. Franz (ZEW and University of Mannheim), H. J. Ramser (University of Konstanz), and K. H. Oppenländer (ifo Institute, Munich) for their support. I also like to thank the Fritz Thyssen Stiftung for financial support of the project, the ifo Institute for providing the data and Thomas Schneeweis for his help with the construction of the data set. Helpful comments from a referee of this journal are gratefully acknowledged. 
the recent growth literature, endogenously determined innovations are seen as the major source of technological advances of firms and the economy. Product innovations increase the quality of the product, and process innovations reduce production costs. Therefore, innovative firms are expected to be more competitive and increase output and employment. On the other hand, product innovations increase product differentiation and tend to reduce competitive pressure. ${ }^{2}$ This can lead to higher prices and less output and employment. In addition, process innovations tend to reduce the labour requirement. Lower prices in the case of lower production costs give rise to positive scale effects of innovations, but technological change tends to favour substitution of labour by capital. In this paper, the impact of innovations on labour demand at the firm level is estimated. Special emphasis is placed on the identification of scale effects, substitution effects, and effects of innovations on competition.

The analysis of labour demand and the dynamic adjustment of employment with respect to changes in the economic environment is also relevant for the short-run analysis of the business cycle. Adjustment costs for employment prevent fast increases of employment in periods of rising demand; the wage-setting behaviour of workers, unions and firms increases the persistence of labour market disequilibria. The rise of those rigidities is blamed for most of the rise of unemployment in Europe since the 1970 s. ${ }^{3}$ In addition, capacity constraints impose a bound on labour demand, at least in the short run. Adjustment costs for investment prevent a fast accumulation of capacities in periods of sufficient demand and increase the persistence of underemployment equilibria. In this paper, the importance of capacity constraints for employment adjustment is estimated. Special emphasis is placed on demand uncertainty and an endogenous adjustment of the working time.

Most theoretical and empirical work on employment adjustment focuses on adjustment costs and the shape of the adjustment cost function. ${ }^{4}$ Another approach focuses directly on the time which is necessary to adjust economic decision variables. ${ }^{5}$ In the model presented here, a delayed adjustment of employment, prices and capacities is discussed. The analysis of a dynamic adjustment permits the consistent introduction of capacity constraints and uncertainty into the model. The analysis of dynamics in terms of adjustment delays and uncertainty simplifies the theoretical analysis. It reduces the dynamic decision problem of the firm into 
a sequence of static decision models which can be solved stepwise. It permits a consistent structural interpretation of the employment adjustment in terms of predetermined capacity constraints and innovations.

The analysis of the dynamic adjustment of employment should also take the competitive situation in the market into account. In industrial economics, the interdependence of the price and quantity adjustment and the nature of competition is emphasized. ${ }^{6}$ Imperfect competition in the product market implies that firms have scope for price setting, and small adjustment costs for prices can translate into large fluctuations of real economic activity. If prices do not clear the market at each moment, quantities react, and more price stickyness increases the volatility of employment. This could mean that the rigidity of prices is as important for the propagation of shocks and unemployment persistence as the rigidity of wages. This implies also that the analysis of employment adjustment can reveal insights into the competitive situation in the market. In this paper, the relation of the employment adjustment at the firm level and indicators of competition in the market such as firm size and innovation activities is explored. The employment adjustment is analysed within a framework of monopolistic competition in the product market. The theoretical model yields testable hypotheses about the direction and the frequency of employment and price adjustments depending on capacity constraints, the autocorrelation and the volatility of demand shocks and the degree of competition in the market.

The main contribution of this paper is the estimation of the employment adjustment with a unique panel of micro data from West German manufacturing firms. The data set contains qualitative quarterly information about the employment adjustment and adjustments of the working time for 2,405 firms during the period 1980-92. The data stem from the regular business survey of the ifo Institute, Munich. In addition, it contains quarterly data on capacity constraints and annual data on firm size and innovation behaviour. The firm-level data provide a valuable source for the analysis of employment rigidities and the microeconomic adjustment of employment and prices with respect to capacity constraints, technological change, and changes in demand and competition. The time-series dimension of the data permits the detailed investigation of the adjustment process, and the high frequency of the data permits the analysis of the volatility of employment adjustment. 


\section{Theoretical model}

\subsection{Capacity constraints and demand uncertainty}

In the theoretical model, a strong separability of firms' decision structure is assumed. ${ }^{7}$ It is assumed that employment and prices adjust only with a delay with respect to demand and cost changes. In the short run, only output is endogenous. Output adjusts with respect to demand with predetermined prices and employment. ${ }^{8}$ The employment adjustment and the price setting take place in the medium run, thus under uncertainty about demand. Investment and innovation behaviour are determined in the long run, which implies that capacities and the production technology are predetermined for the price and employment adjustment.

The assumption of a delayed adjustment of capacities is common in investment models. ${ }^{9}$ Adjustment delays for capital arise from partial irreversibility of investment decisions and the time lag between the decision to invest and the actual implementation and use of capacities. This includes decision lags, delivery lags, time to build and time for the installation of new capital goods. Innovations can be understood as investments in knowledge and, in most cases, changes of the production technology and the introduction of a new product require capital investment. Innovations and investment are complementary and are determined simultaneously. The assumption of a delayed adjustment of the production technology corresponds to the concept of a puttyclay production function.

Delays in the reduction of employment can be justified with legal and contractual periods of notice. In addition, reputation losses for firms in the case of frequent dismissals tend to restrict the downward adjustment of the labour force to normal separations, i.e. quits and retirement. Delays for an upward adjustment of the labour force involve search, screening, and training time. ${ }^{10} \mathrm{~A}$ delayed adjustment of prices corresponds to the assumption of price tags. ${ }^{11}$ The advantage of this assumption, as compared with the assumption of an immediate adjustment and permanent market clearing, is that market disequilibria, price adjustment and adjustment dynamics for employment can be investigated explicitly within the theoretical model.

In most adjustment models, the dynamic adjustment is analysed under the assumption of non-linear adjustment costs. However, it is difficult to find examples for adjustment costs which can account 
for the observed slow adjustment of many economic variables, especially employment and prices. On the other hand, changing decision variables necessarily takes time, and even a short delay between the decision to change employment and/or the price and the realization of a demand shock can introduce considerable uncertainty for the firm. In addition, the analysis of the dynamic adjustment in terms of adjustment delays and uncertainty reduces the dynamic decision problem of the firm to a sequence of static decision models which can be solved stepwise.

The theoretical analysis is carried out within a framework of monopolistic competition in the product market. ${ }^{12}$ In order to distinguish demand shifts, the price elasticity of demand, and demand uncertainty, a log-linear demand curve for the firm's product is assumed,

$$
\ln Y D=\eta \cdot \ln p+\ln Z+\varepsilon, \quad E(\varepsilon)=0, \quad \operatorname{Var}(\varepsilon)=\sigma^{2} .
$$

The time and firm indices are omitted to simplify notation. Each firm faces a firm-specific demand function depending on its price $p$, exogenous or predetermined demand shifts $Z$ and an error term $\varepsilon$. Demand $Y D$ depends negatively on the price with constant elasticity $\eta<-1$; the realized value of the demand shock $\varepsilon$ is not known at the time of the price and employment decision. Supply $Y S$ is determined by a short-run limitational production function with capital $K$ and labour $L$ as inputs,

$$
Y S=\min (Y C, Y L)=\min \left(\pi_{k} \cdot K, \pi_{l} \cdot L\right)
$$

$Y C$ are capacities, $Y L$ is the employment constraint and $\pi_{l}, \pi_{k}$ are the productivities of labour and capital. In the short run, output $Y$ is determined as the minimum of demand and supply, $Y=\min (Y D, Y S)$. The medium-run optimization problem is

$$
\max _{\rightarrow L, p} p \cdot \mathrm{E}(Y)-w \cdot L-c \cdot K,
$$

s.t. equations [1] and [2]. E is the expectation operator. Wage costs $w$ and user costs of capital $c$ are treated as exogenous at the firm level. For the optimal solution, two cases can be distinguished:

1. In the case of capacity constraints, employment is determined from capacities. No more workers will be hired than can be employed with the predetermined capital stock. Supply and employment result from

$$
Y S=Y L=Y C, \quad L(Y C)=Y C / \pi_{l} .
$$


Employment is given by the maximal number of working places $L(Y C)$. Note that short-run substitution of capital and labour is excluded by the assumption of a putty-clay technology. The optimal price depends on capacities, expected demand shifts, demand uncertainty and competition. In the capacity constrained regime, the adjustment of employment is inhibited, and the whole adjustment with respect to expected demand shifts falls on the price.

2. In the case of sufficient capacities, optimal employment and prices are determined from

$$
p(w) \cdot \operatorname{prob}(Y L<Y D) \cdot \pi_{l}-w=0 .
$$

The marginal costs of employment are equal to the wage rate $w$. Marginal returns are determined as the price, multiplied by the productivity of labour, and multiplied by the probability that the additional output can be sold, i.e. if demand exceeds supply (see Figure 1). The optimal price is determined by unit labour costs $w / \pi_{l}$, and the mark-up is equal to the optimal probability of supply constraints on the goods market. The optimal probabilities are determined by the price elasticity of demand and demand uncertainty, i.e. the optimal price is independent of expected demand shifts. Optimal supply and

Figure 1. Optimal employment
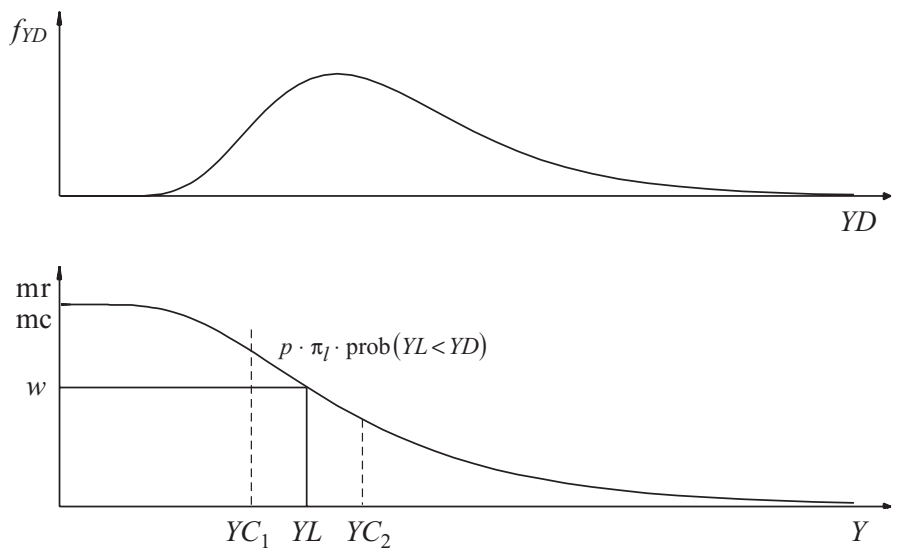

mr: Marginal returns $\quad$ mc: Marginal costs 
employment result from

$$
Y L(w)=\eta \cdot \ln p(w)+\ln Z+\bar{\varepsilon}(\eta, \sigma), \quad L(w)=Y L(w) / \pi_{l} .[6]
$$

In the case of sufficient capacities, the price is independent of expected demand shifts, the firm adjusts quantities. An immediate adjustment of employment is contained as the limiting case $\sigma \rightarrow 0$. Introducing uncertainty reduces the expected utilization of employment and exhibits the same effect on prices and employment as higher variable costs.

The model extends the standard formulation of monopolistic competition by introducing demand uncertainty and medium-run capacity constraints. The assumption of a delayed adjustment of employment and prices enhances the economic interpretation of the model:

- Ex ante, firms set prices and adjust employment under uncertainty about demand, i.e. the firm chooses one point in the $\{p, Y\}$ diagram (see Figure 2). Uncertainty reduces optimal employment and increases the price through the costs of underutilization of employment. Relevant for the employment adjustment is a capacity limit $Y S=Y L \leqslant Y C$ and a minimum price $p(w)$ which is determined by unit labour costs, the price elasticity of demand, and demand uncertainty.

Figure 2. Optimal prices and employment

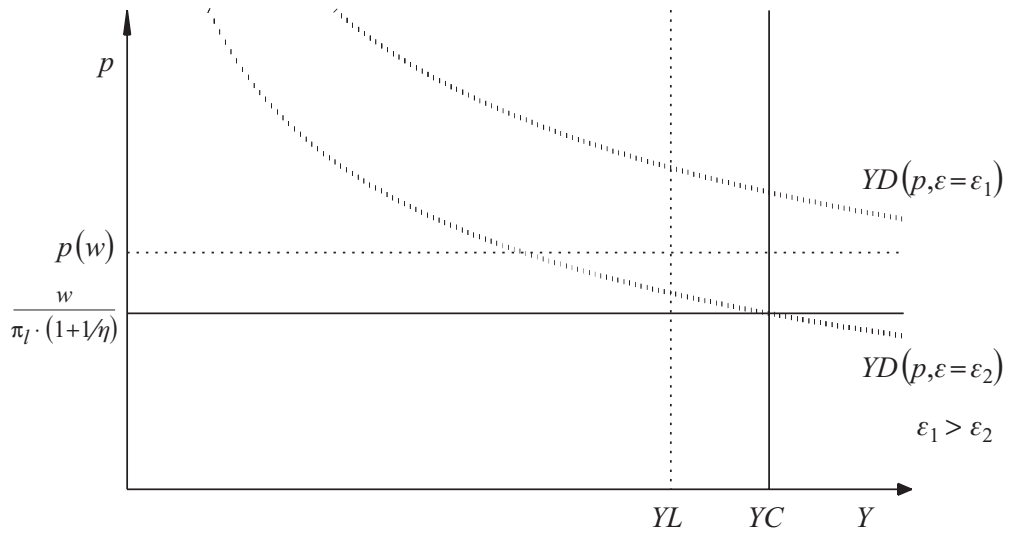


- Ex post, underutilization of employment and capacities or demand rationing can occur. In the case of a negative demand shock, labour hoarding and underutilization of capacities occur, i.e. the model is consistent with the observed procyclically varying productivity of labour. In the case of a positive demand shock, the firm cannot satisfy all customers (delivery lags). Short-run demand shocks can be identified from the utilization of the production factors. The short-run demand situation can be identified from the utilization of employment at the firm level, the medium-run business-cycle situation can be identified from the utilization of capacities.

The model provides a useful framework for the analysis of the employment adjustment and price rigidities during the business cycle. Suppose the stochastic process generating demand shocks is autocorrelated, i.e. firms expect that demand shocks are persistent. Then, unexpected demand shocks affect the utilization of labour and capital today. The adjustment of the firm depends on the availability of capacities. In the case of capacity constraints (in boom periods), employment should remain unchanged and the firm should adjust the price; with sufficient capacities (in recession periods), the firm should adjust employment and the price should remain unchanged. That means the model provides clear testable hypotheses about the effects of capacity utilization $U$ on the direction $\Delta L, \Delta p$ and the frequency $\sigma_{L}, \sigma_{p}$ of employment and price adjustments with respect to demand shocks (see Table 1). The model can be understood as an error-correction model for employment and prices. If the actual utilization differs from the optimum, employment and/or prices adjust.

The dynamic formulation of the model also yields a hypothesis about effects of the price elasticity of demand and demand

Table 1. Competition and capacity utilization

\begin{tabular}{ccccccc}
\hline & $\boldsymbol{U}$ & $\boldsymbol{Z}$ & $|\eta|$ & $\sigma$ & $\omega$ & $\pi_{\boldsymbol{l}}$ \\
\hline$\Delta L$ & + & + & + & - & - & $?$ \\
$\Delta p$ & + & + & - & + & + & - \\
$\sigma_{L}$ & - & & - & + & & \\
$\sigma_{p}$ & + & & + & + & & \\
\hline
\end{tabular}


uncertainty on the employment and price adjustment. ${ }^{13}$ Uncertainty increases the variance of output and should increase the necessity of employment and price changes. It becomes more difficult to achieve a high utilization of capacities and employment. A low price elasticity of demand $|\eta|$ should favour employment adjustments against price adjustments in the case of demand shocks. That means the model also provides a useful framework for the analysis of effects of competition on employment and price adjustments.

Capacity constraints also affect the adjustment of employment and prices with respect to wage and productivity changes. Wage changes affect marginal costs, and in the case of sufficient capacities, employment and prices should adjust. However, in the case of capacity constraints, employment is determined by capacities and the price is determined by expected demand. That means employment and prices should remain unchanged. A similar asymmetry results for productivity changes. In the demand-constrained case, labour productivity increases reduce prices. For meaningful values of the price elasticity of demand, the scale effect of lower prices exceeds the substitution effect that less labour input is necessary to produce output. Therefore, employment should increase. However, in the capacity-constrained case, output is determined by capacities. In this case, higher labour productivity reduces labour demand.

Finally, the model provides a framework for discussing shortrun adjustments of the working time through overtime and shorttime working. The costs of a short-run adjustment of the working time stem from a wage premium for overtime working and a partial compensation of employees for short-time working. The returns stem from more flexibility of supply and output in the case of demand changes. In the case of a positive demand shock and in boom periods, overtime working increases potential supply through the longer working time of labour and capital. This should reduce the volatility of prices. In the case of a negative demand shock, short-time working reduces wage costs for employees who are not needed for current production. This should reduce dismissals and the volatility of employment. That means capacity constraints and a higher volatility of demand should also increase the volatility of the working time.

\subsection{Technological change and competition}

Innovations reduce production costs and increase the quality of the product. Therefore, innovative firms should be more 
competitive and increase output and employment. On the other hand, firms introduce better products to achieve a monopolistic situation in the product market. This could lead to higher prices and less output and employment. In the long run, innovations of other firms destroy the monopolistic situation in the product market, and the process of creative destruction is the driving force of technological change. ${ }^{14}$

Successful product innovations increase the quality of the product. Demand $Z$ increases, and employment should also increase (see Table 2). However, innovations also change competition, and the intended reduction of competitive pressure is an important incentive to introduce innovations. Firms develop differentiated products to become less dependent on the price and the behaviour of other firms in the market. The price elasticity of demand $|\eta|$ and demand uncertainty $\sigma$ should be lower for specialized products. ${ }^{15}$ Less competition should result in higher prices and less employment; less demand uncertainty should result in lower prices and more employment. In addition, less competition should favour quantity adjustments against price adjustments, while less uncertainty about demand should reduce the necessity of both price and quantity adjustments.

Process innovations affect supply. They increase labour productivity $\pi_{l}$ and reduce production costs, which should result in lower prices and more output. The employment effect is ambiguous. More output implies a positive scale effect, but process innovations often imply a labour-saving technique, i.e. less labour is necessary to produce output. In the demand-constrained regime, the scale

Table 2. Technological change and competition

\begin{tabular}{|c|c|c|c|c|c|}
\hline & \multicolumn{2}{|c|}{ Own innovations } & \multicolumn{2}{|c|}{ Others' innovations } & \multirow[b]{2}{*}{ Firm size } \\
\hline & Product & Process & Product & Process & \\
\hline$\sigma$ & $?$ & & - & + & - \\
\hline$|\eta|$ & - & & - & + & - \\
\hline$Z$ & + & & - & - & \\
\hline$\pi_{l}$ & & + & & & + \\
\hline$\Delta L$ & $?$ & $?$ & - & - & $?$ \\
\hline$\Delta p$ & + & - & $?$ & - & $?$ \\
\hline $\bar{\sigma}_{L}$ & $?$ & & ? & ? & $?$ \\
\hline$\sigma_{p}$ & - & & - & + & - \\
\hline
\end{tabular}


effect exceeds the substitution effect, but in the capacityconstrained regime, output is determined by capacities and only the substitution effect prevails. Therefore, process innovations might reduce labour demand.

Demand also depends on innovations of other firms in the market. First, more competition from other firms with better products and lower prices should reduce demand and employment. Second, others' innovations also change competition. It can be argued that a market dominated by product innovators exhibits a lower price elasticity of demand. This should lead to higher prices, less employment and a higher volatility of employment. In addition, the variance of demand shocks will be lower. Each firm is protected from competition through specialized products. The cross-price elasticity of demand is lower, which should reduce the volatility of employment and prices. In markets that are characterized by a large share of process innovators, a higher price elasticity of demand and more demand uncertainty is expected. Therefore, more price competition is expected and the effect on the volatility of employment is ambiguous.

Finally, employment adjustment depends on firm size. First, scale economies in large firms should reduce production costs which permits them to set lower prices and increase output and employment. Second, adjustment costs for prices and employment might differ according to firm size. Third, large firms exhibit larger market shares, which should be associated with less competition and less uncertainty about demand shocks. Therefore, it is not clear from theoretical arguments whether large firms increase employment and whether the volatility of employment will be lower. The aim of the empirical work is to test the hypotheses of the theoretical model and to estimate those effects which are ambiguous from theoretical arguments.

\section{Empirical analysis}

\subsection{Data and empirical specification}

The basic data source for the empirical investigation of employment adjustment is a unique panel of micro data from West German manufacturing firms. The data stem from the business survey of the ifo Institute, Munich; the data set contains information from 2,405 firms for the period 1980-92. The data set firstly contains 
qualitative information about the employment adjustment. Every quarter, the firms were asked whether the number of employees for a specific product would increase $l^{+}$, decrease $l^{-}$, or remain constant $l^{=}$within the next 3 months (seasonally adjusted). The firms were also asked whether they exhibit overtime working $h^{\circ}$, more than customary overtime working $h^{*}$ and short-time working $h^{s}$. The data reveal that adjustments of the working time are highly correlated with employment changes. Firms that exhibit (more than customary) overtime working more often report employment increases, and firms that exhibit short-time working more often report employment reductions.

Corresponding quantitative information about employment changes is available annually for about two-thirds of the firms. The cross-sectional variance of employment changes is enormous: the standard deviation of the rate of change of employment for each year is about 10 percent. The reliability of the qualitative data on the employment adjustment was tested with an OLS regression of quantitative changes on the number of reported qualitative changes. The results revealed that firms which more often report employment increases (reductions) during the year exhibit more (less) employment growth; each reported qualitative employment change corresponds to about a 3 percent average change of employment, i.e. the qualitative data appear to be consistent. The time-series development of the share of firms reporting employment increases and decreases is depicted in Figure 3.

For the empirical analysis, the sequential decision structure of the theoretical model is exploited for the econometric specification. In the theoretical model, capacities and innovation behaviour are determined in the long run; therefore, they can be treated as predetermined for the medium-run employment and price decision. In addition, the specification of the adjustment model is based on the assumption that firm-specific demand shocks are autocorrelated. The firms exploit this autocorrelation when forming expectations about the development of demand. A positive demand shock today increases capacity utilization today. If the firm expects that the higher demand will persist, it will increase employment and/or prices tomorrow. The model can be understood as an error-correction model for employment adjustment. These assumptions permit the interpretation of lagged values of capacity utilization and innovations as predetermined for the employment adjustment, and identification of the model is sought through lagged values of the explanatory variables. 
Figure 3. Employment changes and capacity utilization.
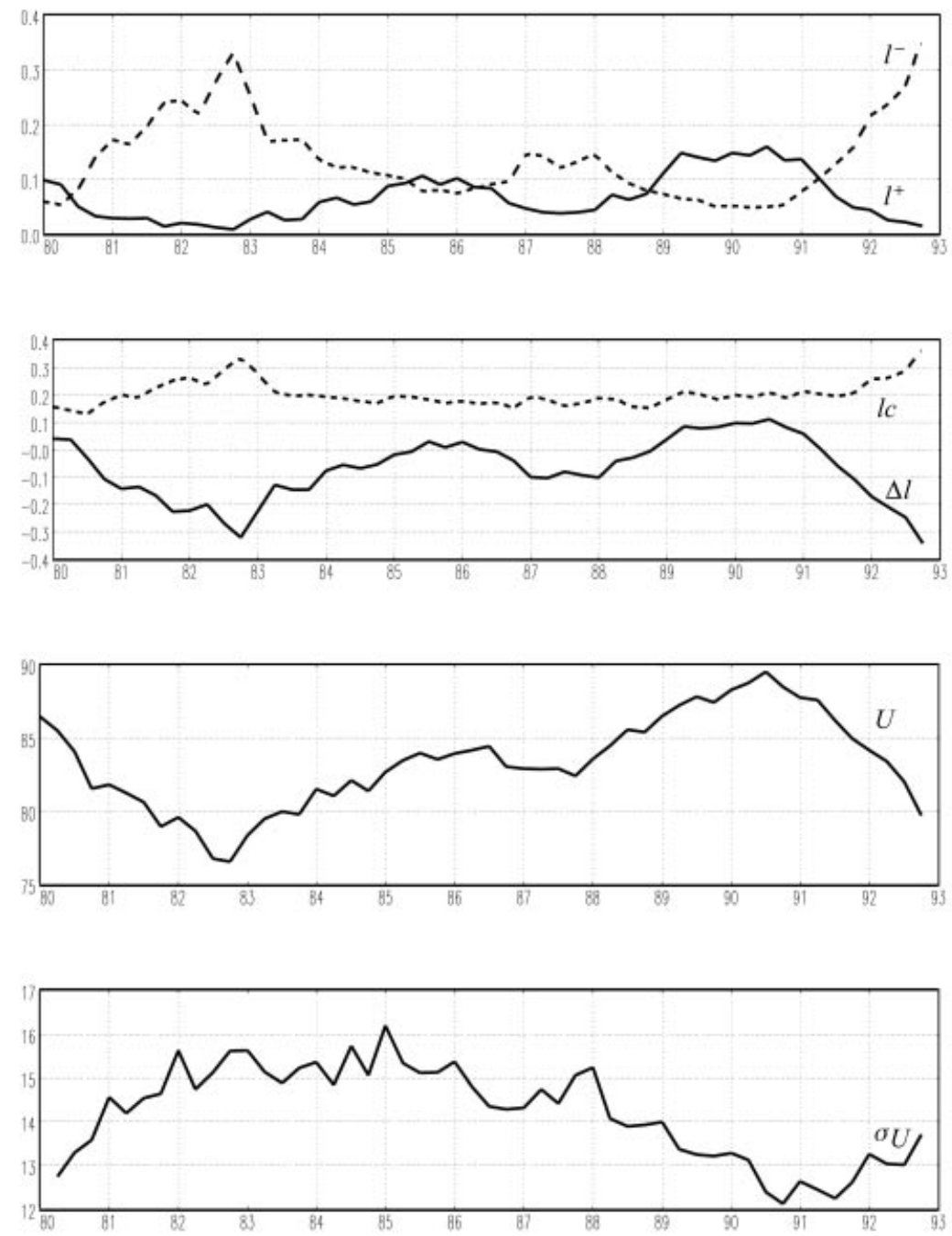

Source: Ifo firm panel, 2,405 firms, 1980-92.

The empirical specification of the model is based on annual data, i.e. the annual number of employment increases, decreases, net increases ${ }^{16}$ and changes is determined by 1 -year-lagged values of the explanatory variables (ordered probit models). Corresponding models are estimated for adjustments of the working time. For the 
quantitative data, an OLS model for the rate of change of employment is specified. Finally, corresponding models for net price increases and price changes are specified. This should provide information about the determinants of the price adjustment as compared with the employment adjustment. For the estimates, the data are pooled and an unbalanced panel is employed. Note that the endogenous variables are already specified as changes.

The first explanatory variable is the degree of capacity utilization $U$. For the estimates, a binary specification of this variable is chosen to take a non-linear effect of capacity constraints on the employment adjustment into account. Five dummy variables are calculated according to the average capacity utilization during the year. The data on capacity utilization are also used to calculate a measure of the volatility of demand shocks at the firm level. For the estimates, two dummy variables are calculated according to the standard deviation $\sigma_{U}$ of the quarterly data. In addition, it is tested whether the increase or decrease of capacity utilization $\Delta U$ during the year affects the employment adjustment. Two dummy variables are calculated according to the difference of the reported values in December versus March of the previous year.

Once a year, in December, the business survey contains information on whether within the year for the respective product an innovation was implemented. Innovations are defined as novelties or essential improvements of the product or the production technique; the answers are distinguished for product and process innovations. For the estimates, dummy variables are defined for product and process innovators. The innovation behaviour of the other firms in the market is approximated by the average share of innovators in the sector (two-digit industry classification); these shares are calculated excluding the respective firm. Firm size is specified with dummy variables according to the average number of employees $\bar{l}$ of the firm over the sample. Although large firms are over-represented in the survey, as compared with total manufacturing, the sample consists mainly of small and medium-size firms.

Finally, the impact of technological change and competition on the volatility of demand is estimated. For this purpose, OLS and ordered probit models for the rate of capacity utilization, the standard deviation of capacity utilization, and the change of capacity utilization are specified. Explanatory variables are own innovation activities, the share of innovators in the sector, and firm 
size. A complete set of 11 time dummies is always included in the estimates. These dummies capture the development of factor costs, since firm-level data on input costs are not available from the business survey. ${ }^{17}$

\subsection{Estimation results}

The estimation results are presented in Table 3. The endogenous variables are depicted at the top of the table. Below, the estimated coefficients and $t$-statistics (in parentheses) of the explanatory variables are reported. The sample means of the endogenous variables, and the $\chi^{2}$ statistic and the number of observations of the estimated equations are reported at the bottom of the table. The explanatory variables refer to the preceding year.

The estimation results reveal, firstly, that a high capacity utilization $U$ reduces the frequency of employment reductions $l^{-}$ and increases the frequency of employment increases $l^{+}$. Consequently, the effect on net employment increases $\Delta l$ is also positive. A consistent result is achieved for the rate of change of employment $\Delta \ln L$. The quantitative impact of capacity utilization on employment is large: firms that exhibit a capacity utilization rate of at least 90 percent exhibit about a 5 percentage points higher rate of change of employment, as compared with those firms that exhibit a capacity utilization of less than 60 percent, the reference case. Thus the level of capacity utilization today is a useful predictor of employment changes tomorrow.

A high capacity utilization also increases the frequency of (more than customary) overtime working $h^{o}, h^{*}$ and reduces the frequency of short-time working $h^{s}$. Capacity constraints also increase the frequency of net price increases $\Delta p$. This confirms the theoretical modelling of the price and quantity adjustment. In the case of positive autocorrelation of demand shocks, a high utilization of capacities indicates a positive demand shock today. In the short run, the firm should adjust the working time; in the medium run, the firm should increase employment and/or prices.

In addition, a high capacity utilization significantly reduces the volatility of employment $\sigma_{l}$ and increases the volatility of prices $\sigma_{p}$. This is again consistent with the theoretical model. In the case of a low utilization of capacities, employment should change often and prices should remain constant; in the case of capacity constraints, employment adjustment is inhibited and prices should change 
Table 3. Employment, working time and prices

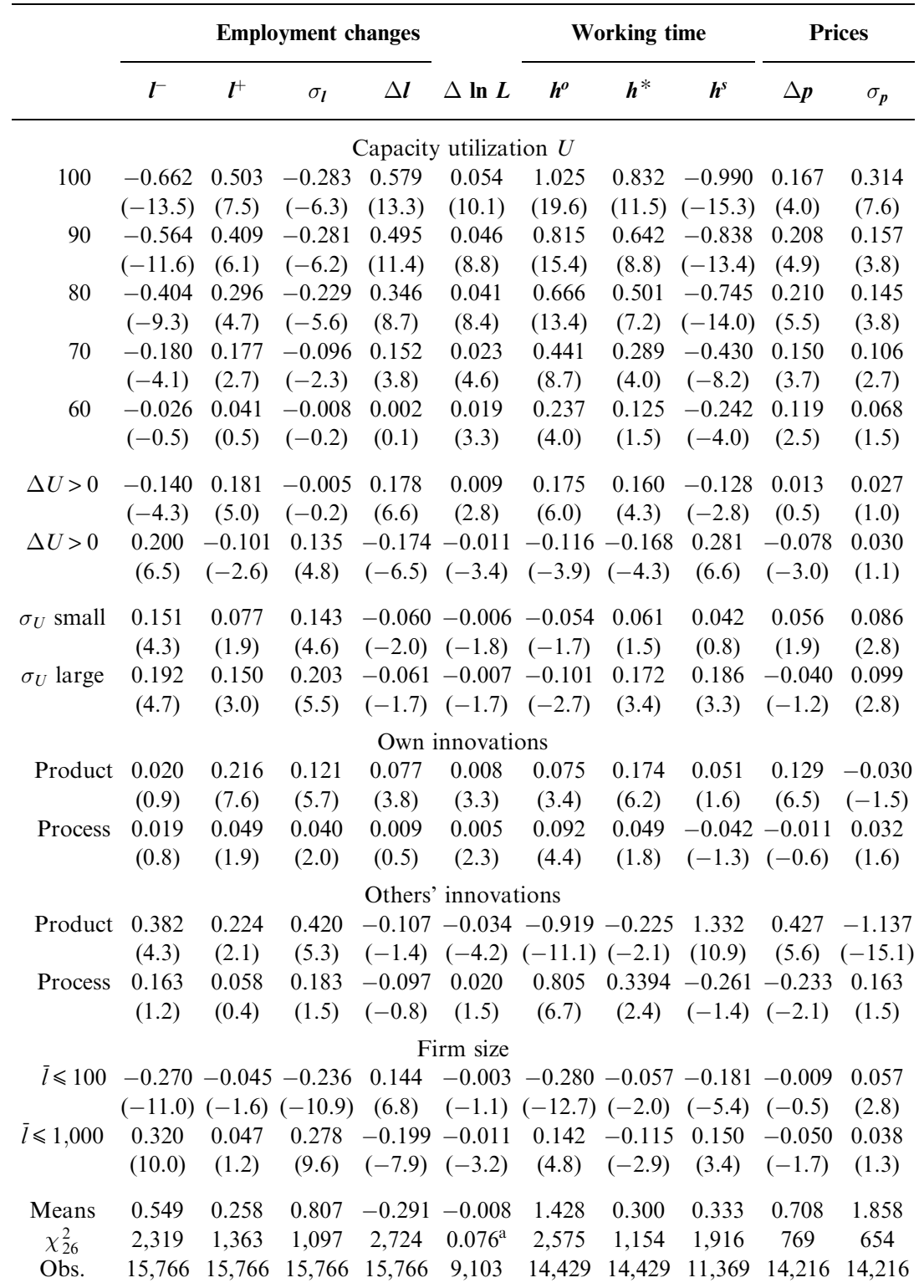

Notes: Ordered probit models, OLS for $\Delta \ln L . U<60, \Delta U=0, \sigma_{U}=0$, and $100<\bar{l}<1,000$ are the reference cases. $t$-statistics are shown in parentheses. Time dummies for each year were included (not reported).

${ }_{a}^{a} \bar{R}^{2}$ is reported. 
often. Capacity constraints are an important determinant of the relative volatility of prices and quantities.

The change of capacity utilization $\Delta U$ also exhibits a significant impact on employment adjustment. In the case of an increase $\Delta U>0$, the frequency of employment reductions is lower, and the frequency of (net) increases and the rate of change of employment are higher. The reverse result is achieved for $\Delta U<0 .{ }^{18} \mathrm{~A}$ consistent result is revealed for adjustments of the working time.

As expected, a large variance of capacity utilization $\sigma_{U}$ increases the volatility of employment; it increases the frequency of increases, reductions and changes. The net effect on employment $\Delta l, \Delta \ln L$ is negative, i.e. a high volatility of demand shocks and capacity utilization tends to reduce labour demand. Surprisingly, a large variance of capacity utilization tends to reduce (customary) overtime working $h^{o}$. However, it increases the frequency that firms report more than customary overtime working $h^{*}$ and shorttime working $h^{s}$. Note that a high volatility of demand also increases the frequency of price changes.

These estimates reveal a consistent picture of employment adjustment during the business cycle. A high capacity utilization indicates a positive demand shock today. The firms adjust with increasing hours, employment and prices. In addition, capacity constraints reduce the volatility of employment and increase the volatility of prices. In boom periods, employment adjustments are restricted and the firms change prices. A high volatility of demand shocks increases the necessity of price and employment adjustments, and the net effect of demand uncertainty on employment is negative.

In the next rows, the effects of innovations on the employment adjustment are depicted. The estimation results reveal that product innovators more often increase employment, and the effect on employment reductions is positive but not significant. Consequently, the effects on employment changes and net employment increases are positive. The effect on overtime working is also positive. Product innovators also increase prices frequently but less often change them; i.e. they less often reduce prices. The estimation results for the impact of innovations (and firm size) on capacity utilization are reported in Table 4. (OLS and ordered probit models for the level of capacity utilization $U$, its standard deviation $\sigma_{U}$, and its change $\Delta U) .{ }^{19}$ The results reveal that product innovators also exhibit a higher level of capacity utilization; the effect on the volatility of capacity utilization is negative, albeit barely significant. 
Table 4. Capacity utilization

\begin{tabular}{|c|c|c|c|c|c|c|}
\hline & \multicolumn{2}{|c|}{$\boldsymbol{U}$} & \multicolumn{2}{|c|}{$\sigma_{U}$} & \multicolumn{2}{|c|}{$\Delta \boldsymbol{U}$} \\
\hline & OLS & Ordered & OLS & Ordered & OLS & Ordered \\
\hline \multicolumn{7}{|c|}{ Own innovations } \\
\hline Product & $\begin{array}{l}1.516 \\
(7.4)\end{array}$ & $\begin{array}{l}0.115 \\
(6.7)\end{array}$ & $\begin{array}{c}-0.136 \\
(-1.6)\end{array}$ & $\begin{array}{c}-0.009 \\
(-0.5)\end{array}$ & $\begin{array}{c}0.035 \\
(0.2)\end{array}$ & $\begin{array}{l}-0.007 \\
(-0.4)\end{array}$ \\
\hline Process & $\begin{array}{l}1.722 \\
(8.8)\end{array}$ & $\begin{array}{c}0.132 \\
(8.0)\end{array}$ & $\begin{array}{l}-0.455 \\
(-5.4)\end{array}$ & $\begin{array}{l}-0.077 \\
(-4.3)\end{array}$ & $\begin{array}{c}-0.005 \\
(-0.0)\end{array}$ & $\begin{array}{l}-0.014 \\
(-0.7)\end{array}$ \\
\hline \multicolumn{7}{|c|}{ Others' innovations } \\
\hline & $\begin{array}{l}-1.453 \\
(-1.9)\end{array}$ & $\begin{array}{l}-0.070 \\
(-1.1)\end{array}$ & $\begin{array}{l}-0.772 \\
(-2.4)\end{array}$ & $\begin{array}{c}-0.340 \\
(-5.0)\end{array}$ & $\begin{array}{c}0.779 \\
(1.1)\end{array}$ & $\begin{array}{l}-0.028 \\
(-0.4)\end{array}$ \\
\hline Process & $\begin{array}{l}-3.198 \\
(-2.8)\end{array}$ & $\begin{array}{c}-0.340 \\
(-3.5)\end{array}$ & $\begin{array}{c}-0.318 \\
(-0.6)\end{array}$ & $\begin{array}{c}0.164 \\
(1.6)\end{array}$ & $\begin{array}{c}-1.978 \\
(-1.8)\end{array}$ & $\begin{array}{l}-0.115 \\
(-1.0)\end{array}$ \\
\hline \multicolumn{7}{|c|}{ Firm size } \\
\hline $\bar{l}<100$ & $\begin{array}{l}-4.923 \\
(-24.9)\end{array}$ & $\begin{array}{l}-0.379 \\
(-22.9)\end{array}$ & $\begin{array}{l}0.906 \\
(10.8)\end{array}$ & $\begin{array}{c}0.126 \\
(7.1)\end{array}$ & $\begin{array}{c}-0.360 \\
(-1.9)\end{array}$ & $\begin{array}{l}-0.017 \\
(-0.9)\end{array}$ \\
\hline $\bar{l} \geqslant 1000$ & $\begin{array}{c}0.774 \\
(2.4)\end{array}$ & $\begin{array}{c}0.071 \\
(2.6)\end{array}$ & $\begin{array}{l}-0.816 \\
(-6.0)\end{array}$ & $\begin{array}{l}-0.170 \\
(-5.7)\end{array}$ & $\begin{array}{c}0.636 \\
(2.1)\end{array}$ & $\begin{array}{c}0.079 \\
(2.6)\end{array}$ \\
\hline Means & 83.15 & 2.868 & 5.589 & 2.189 & -1.213 & 1.930 \\
\hline$\chi_{17}^{2}$ & $0.106^{\mathrm{a}}$ & 2.091 & $0.029^{\mathrm{a}}$ & 533 & $0.031^{\mathrm{a}}$ & 646 \\
\hline Obs. & 19,907 & 19,907 & 19,907 & 19,907 & 17,926 & 17,926 \\
\hline
\end{tabular}

Notes: $t$-statistics are shown in parentheses. Time dummies for each year were included (not reported).

${ }^{\mathrm{a}} \bar{R}^{2}$ is reported.

Taken together, the results imply that product innovators are more successful: they exhibit a higher utilization of labour and capital, increase employment, and set higher prices. The quantitative impact is non-negligible: product innovators exhibit nearly a 1 percentage point higher rate of change of employment. In addition, product innovations increase the volatility of employment (and the working time) but reduce the volatility of prices. This result is consistent with effects of innovations on competition. Product innovators sell specialized products in monopolistic markets where the price elasticity of demand is low. A lower price elasticity of demand, in turn, favours employment adjustments against price adjustments. Note that the positive effect of product innovations on employment implies that the scale effect of a better product exceeds the negative effect of less price competition.

Process innovations exhibit only a small effect on employment adjustment. The frequency of employment increases and changes is 
slightly higher, but these effects are only weakly significant. However, process innovators more often exhibit overtime working and less often exhibit short-time working. In addition, they exhibit a higher level and a lower volatility of capacity utilization. This is consistent with higher capital costs which enhance the incentives for achieving a high capacity utilization through adjustments of the working time. Note that the effects of innovations on the level and the volatility of capacity utilization imply that the total effect on employment is enhanced. Innovations increase capacity utilization and reduce demand volatility which, in turn, increase employment.

A strong effect on employment and price adjustment is revealed for the share of product innovators in the market. In sectors dominated by product innovators, the frequency of employment increases, reductions and changes is higher, i.e. the volatility of employment is higher. In addition, the frequency of price adjustments is much lower, and the effect on net price increases is positive. This confirms that product innovations affect competition. In those sectors, price competition is replaced by competition in innovation behaviour. When prices are sticky, quantities adjust more often in the case of demand changes. Note that the effect of the share of product innovators on the volatility of capacity utilization is negative. In those sectors, demand uncertainty is lower. In addition, the net effect on employment, working time and capacity utilization is negative. Better products of competitors reduce demand, capacity utilization, working time and employment.

The share of process innovators in the sector exhibits only small and insignificant effects on the employment adjustment. The effect on working time is positive. This indicates that others' process innovations enhance the incentives to achieve a high utilization of capacities through an increase of the working time. Nevertheless, capacity utilization is lower and the effect on price increases is negative: a better production technique by competitors reduces demand for the firm, prices and capacity utilization.

Finally, firm size exhibits a highly significant effect on employment adjustment. The estimation results reveal that the frequency of employment adjustments is lower in small firms $\bar{l} \leqslant 100$ and higher in large firms $\bar{l} \geqslant 1,000$, as compared with medium-size firms, the reference group. The effect of firm size on net employment increases is negative, ceteris paribus. Note, however, that large firms exhibit a higher probability of innovations (see Table 5), which increases the volatility of employment further but 
Table 5. Innovations and firm size

\begin{tabular}{lllll}
\hline & $\overline{\boldsymbol{l}} \leqslant \mathbf{1 0 0}$ & $\mathbf{1 0 0}<\overline{\boldsymbol{l}}<\mathbf{1 , 0 0 0}$ & $\overline{\boldsymbol{l}} \geqslant \mathbf{1 , 0 0 0}$ & All \\
\hline Product innovations & 0.325 & 0.581 & 0.743 & 0.497 \\
Process innovations & 0.322 & 0.519 & 0.690 & 0.459
\end{tabular}

The average share of innovators according to firm size, is depicted.

reduces the negative firm size effect on net employment increases. Large firms also exhibit a higher capacity utilization rate and a lower volatility of capacity utilization, i.e. they face less demand uncertainty. This implies that the total firm-size effect on employment changes is lower. These results indicate that small firms sell on markets which exhibit a higher price elasticity of demand $|\eta|$ and/or face higher adjustment costs for employment. However, firm size exhibits only a small effect on price setting, ceteris paribus. Finally, the lower frequency of overtime and short-time working time in small firms strengthens the argument that it is more difficult for them to adjust the labour input.

\section{Conclusions}

In this paper, the employment adjustment at the firm level is estimated with a large panel of business survey data from West German manufacturing. The micro data provide a valuable source for the analysis of employment adjustment with respect to changes in demand and competition. The time-series dimension of the data permits the detailed investigation of the adjustment process, and the high frequency of the data permits the analysis of the volatility of employment. The estimates are based on a theoretical model of monopolistic competition in the product market and a delayed adjustment of employment and prices. Special emphasis is placed on the effects of demand uncertainty, capacity constraints, technological change and competition. The theoretical model yields testable hypotheses about the direction and the frequency of employment and price adjustments depending on capacity utilization, the volatility of demand, innovations and firm size.

The estimation results reveal that capacity constraints exhibit a very important effect on employment adjustment. A high capacity utilization today increases the working time, employment and 
prices tomorrow, which indicates a positive autocorrelation of demand shocks and confirms the imposed adjustment structure of the theoretical model. A high utilization of capacities also reduces the volatility of employment and increases the volatility of prices, which confirms the relevance of capacity constraints for the price and quantity adjustment. A high variance of demand shocks increases the necessity of employment adjustments, adjustments of the working time and price adjustments.

Technological change exhibits a significant positive effect on employment at the firm level. Innovators are more successful, exhibit a higher capacity utilization and increase employment and the working time; product innovations exhibit a stronger effect on employment than process innovations. The employment adjustment is also affected significantly by competition. Product innovators change employment frequently, and in markets that are characterized by a large share of product innovators, prices are sticky and employment adjustments are frequent. Innovations affect competition, price competition is replaced by competition of innovation behaviour, and firms more often adjust quantities with respect to demand shocks. Finally, employment adjustments and adjustments of the working time are more frequent in large firms, despite their higher level and their lower volatility of capacity utilization.

The analysis of the dynamic adjustment of employment with respect to changes in the economic environment is relevant for the short-run analysis of the business cycle as well as for the analysis of the long-run development of competition. Micro data from firms supply valuable information for the analysis of employment and price adjustment. These data are available from regular business surveys for many countries and for long periods, and cross-country comparisons of the adjustment process are feasible. A more detailed analysis of the adjustment of employment versus prices with respect to changes in technology, costs, demand and competition and the determinants of the employment adjustment at the firm level should remain on the agenda of future research.

\section{Notes}

\footnotetext{
${ }^{1}$ See Zimmermann (1991), Mortensen and Pissarides (1995) and Meghir et al. (1996).

${ }^{2}$ See Kamien and Schwarz (1975) and Cohen and Levin (1989).
} 
${ }^{3}$ See Nickell (1990) and Bean (1994).

${ }^{4}$ See Davis and Haltiwanger (1992), Caballero and Engel (1992a), Caballero et al. (1995) and Baily et al. (1996). Overviews are provided by Nickell (1986) and Hamermesh and Pfann (1996).

${ }^{5}$ Kydland and Prescott (1982) develop a model of time to build for investment.

${ }^{6}$ See Barro (1972), Hall (1986), Blanchard and Kiyotaki (1987), Carlton (1989) and Caballero and Engel (1992b).

${ }^{7}$ For a more detailed discussion of the theoretical model, see Smolny (1998a).

${ }^{8}$ The discussion of an endogenous adjustment of the working time is postponed to the end of this section.

${ }^{9}$ For a discussion of adjustment delays, see Nickel (1978) and Kydland and Prescott (1982).

${ }^{10}$ See Blanchard and Diamond (1992) and Hamermesh and Pfann (1996).

${ }^{11}$ See Maccini (1981), Andersen (1996) and Smolny (1998a).

${ }^{12}$ See Dixit and Stiglitz (1977) and Blanchard and Kiyotaki (1987).

${ }^{13}$ For a discussion, see Barro (1972), Carlton (1989) and Blanchard and Kiyotaki (1987).

${ }^{14}$ See Aghion and Howitt (1992). For a discussion of the relation between market structure and innovations, see Kamien and Schwarz (1975), Dixit and Stiglitz (1977), Cohen and Levin (1989) and Smolny (1998b).

${ }^{15}$ The introduction of a new product might also increase uncertainty about demand. In addition, better products might be more expensive to produce.

${ }^{16} \mathrm{Net}$ increases are defined as the number of increases minus the number of decreases during the year. The sample is constrained to those observations where complete annual information is available.

${ }^{17}$ Using the available industry-level data of wages is questionable. In addition, preliminary estimates with those data yield inconclusive results.

${ }^{18} \mathrm{~A}$ constant capacity utilization $\Delta U=0, \sigma_{U}=0$ is the reference case. $\sigma_{U}$ large is defined as $\sigma_{U}$ above 5 percentage points.

${ }^{19}$ The specification of the ordered variables is equal to those of the corresponding explanatory variables in Table 3.

\section{References}

Aghion P. and Howitt P. (1992) 'A Model of Growth through Creative Destruction', Econometrica, 60: 323-351.

Andersen T. M. (1996) 'Rationing of Sales and Price Setting', European Economic Review, 40 (7): 1441-1451.

Baily M., Bartelsman E. J. and Haltiwanger, J. (1996) 'Labor Productivity: Structural Change and Cyclical Dynamics'. Working Paper 5503, National Bureau of Economic Research.

Barro R. J. (1972) 'A Theory of Monopolistic Price Adjustment', Review of Economic Studies, 39: 17-26.

Bean C. R. (1994) 'European Unemployment: A Survey'. Journal of Economic Literature, 32: 573-619.

Blanchard O. J. and Diamond P. (1992) 'The Flow Approach to Labor Markets', American Economic Association, Papers and Proceedings, 82 (2): 354-59. 
Blanchard O. J. and Kiyotaki N. (1987) 'Monopolistic Competition and the Effects of Aggregate Demand', American Economic Review, 77: 647-666.

Caballero R. J. and Engel E. M. R. A. (1992a) 'Microeconomic Adjustment Hazards and Aggregate Dynamics', Working Paper 4090, National Bureau of Economic Research.

Caballero R. J. and Engel E. M. R. A. (1992b) 'Price Rigidities, Asymmetries, and Output Fluctuations', Working Paper 4091, National Bureau of Economic Research.

Caballero R. J., Engel E. M. R. A. and Haltiwanger J. (1995) 'Aggregate Employment Dynamics: Building from Microeconomic Evidence', Working Paer 5042, National Bureau of Economic Research.

Carlton D. W. (1989) 'The Theory and the Facts of How Markets Clear: Is Industrial Organization Valuable for Understanding Macroeconomics?' in Schmalensee R. and Willig R. D. (eds.) Handbook of Industrial Organization, Vol. I, Amsterdam: Elsevier: 909-946.

Cohen W. M. and Levin R. C. (1989) 'Empirical Studies of Innovation and Market Structure' in Schmalensee R. and Willig R. D. (eds.) Handbook of Industrial Organization, Vol. II, Amsterdam: Elsevier: 1059-1107.

Davis S. J. and Haltiwanger J. (1992) 'Gross Job Creation, Gross Job Destruction, and Employment Reallocation', Quarterly Journal of Economics, 107 (3): 819-863.

Dixit A. K. and Stiglitz J. E. (1977) 'Monopolistic Competition and Optimum Product Diversity', American Economic Review, 67 (3): 297-308.

Hall R. E. (1986) 'Market Structure and Macroeconomic Fluctuations', Brookings Papers on Economic Activity, 2: 285-338.

Hamermesh D. S. and Pfann G. A. (1996) 'Adjustment Costs in Factor Demand', Journal of Economic Literature, 34 (3): 1264-1292.

Kamien M. I. and Schwarz N. L. (1975) 'Market Structure and Innovation: A Survey', Journal of Economic Literature, 13: 1-37.

Kydland F. E. and Prescott, E. C. (1982) 'Time to Build and Aggregate Fluctuations', Econometrica, 50 (6): 1345-1370.

Maccini L. J. (1981) 'On the Theory of the Firm Underlying Empirical Models of Aggregate Price Behavior', International Economic Review, 22 (3): 609-624.

Meghir C., Ryan A. and van Reenen J. (1996) 'Job Creation, Technological Innovation and Adjustment Costs: Evidence from a Panel of British Firms', Annales d'Economie et de Statistique, 41 (42): 255-274.

Mortensen D. T. and Pissarides C. A. (1995) 'Technological Progress, Job Creation and Job Destruction. Working Paper 264, Center for Economic Policy Performance.

Nickell S. J. (1978) The Investment Decision of Firms, Cambridge: Cambridge University Press.

Nickell S. J. (1986) 'Dynamic Models of Labour Demand' in Ashenfelter O. and

Layard R. (eds.) Handbook of Labor Economics, Vol. I, Amsterdam: Elsevier: $475-522$.

Nickell S. J. (1990) 'Unemployment: A Survey', The Economic Journal 100: 391-439.

Smolny W. (1998a) 'Monopolistic Price Setting and Supply Rigidities in a Disequilibrium Framework', Economic Theory, 11: 157-169.

Smolny W. (1998b) 'Innovations, Prices, and Employment - A Theoretical Model and an Empirical Application for West German Manufacturing Firms', Journal of Industrial Economics, XLVI (3): 359-381. 
Zimmermann K. F. (1991) 'The Employment Consequences of Technological Advance, Demand and Labor Costs in 16 German Industries', Empirical Economics, 16: 253-266. 